\title{
Avaliação de políticas públicas: uma nova fronteira para o Controle Externo e pilar estruturante da democracia
}

\author{
Public Policy Analysis: a new frontier for external control \\ and democracies' structural pillar
}

\author{
Sebastião Helvecio Ramos de Castro ${ }^{1}$ \\ Renata Ramos de Castro ${ }^{2}$
}

\section{RESUMO}

Este trabalho destina-se ao debate acadêmico e, ainda, prático e crítico da superação paradigmática na avaliação de políticas públicas realizada pelos Tribunais de Contas como representantes principais do controle externo. Assim, a consequência destas reflexões é o papel preservado e reafirmado das atividades de controle e monitoramento para garantir a democracia. Realizado por meio da metodologia indutiva, com revisão bibliográfica e legislativa, cria-se o contexto essencial para a supramencionada análise crítica.

Palavras-Chave: Controle de Políticas Públicas. Avaliação Ex-Ante. Avaliação Ex-Post.

\footnotetext{
1 Conselheiro do Tribunal de Contas do Estado de Minas Gerias. Doutor em saúde coletiva pela Universidade do Estado do Rio de Janeiro. Especialista em análise de dados para o controle externo pela Escola de Contas e Capacitação Professor Pedro Aleixo. Especialista em controle externo e avaliação de gestão pública pela Pontifícia Universidade Católica de Minas Gerais. Especialista em didática do ensino superior pela Universidade Federal de Juiz de Fora. Bacharel em direito pela Faculdade de Ciências Contábeis e Jurídicas Vianna Júnior. Médico graduado pela Faculdade de Medicina da Universidade Federal de Juiz de Fora. E-mail: sebastiaohelvecio@tce.mg.gov.br 2 Consultora Jurídica na R. Santana Consultoria e Capacitação. Advogada-sócia da Ramos e Santana Advogados Associados. Sócia-diretora e consultora jurídica na TRweb Soluções Tecnológicas e Consultoria. Professora e fundadora da Estud'Arte Jurídica. Mestre em direito pela Universidade Federal de Minas Gerais. Especialista em direito público global pela Universidad Castilla-La Mancha. Especialista em justiça pela Harvard University. Especialista em direito internacional pelo Centro de Direito Internacional. Especialista em direito humanitário pela London School of Economics and Political Science. MBA em gerenciamento de projetos pelo IBMEC-MG. E-mail: renata@rsantana.com.br
}

Rev. Controle, Fortaleza, v. 19, n.1, p. 21-38, jan./jun. 2021. 


\section{ABSTRACT}

This work is intended for the academic debate and, still, practical and critical of the paradigmatic overcoming in the evaluation of public policies carried out by the Courts of Accounts, as main representatives of External Control. Thus, from these reflections, we have the arrival point: the preserved and reaffirmed role of control activities and monitoring to guarantee democracy. Performed through the inductive methodology, with bibliographic and legislative revision, it creates the essential context for the aforementioned critical analysis.

Keywords: Public Policy Control. Ex-Ante Evaluation. Ex-Post Evaluation.

Recebido: 07-12-2020

Aprovado: 11-12-2020

\section{INTRODUÇÃO}

O interesse no tema "políticas públicas" é tanto antigo quanto cosmopolita. Por isso é que não constitui objetivo deste trabalho traçar a origem delas, justamente porque incontáveis capítulos de livro e artigos especializados esgotaram o tema (ARROW, 1951) por si só. Porém, em apertada síntese, podemos inferir que a política pública como disciplina acadêmica surge nos Estados Unidos da América, dando ênfase nos estudos focados nas ações de governo. A RAND Corporation (Research and Development Corporation), organização não governamental que recebe recursos públicos, foi formalmente criada em $1^{\circ}$ de novembro de 1948 e pode ser considerada a pioneira das think tanks. Uma equipe multidisciplinar constituída por matemáticos, sociólogos, cientistas políticos, enge- 
nheiros e analistas de sistemas reuniu-se para, inspirados pela teoria dos jogos de Neumann, estudar como uma guerra poderia ser racionalizada. Deste estudo surge a proposição de aplicar métodos científicos às propostas para as tomadas de decisão governamentais em todo o espectro da administração pública (BACHRACHB; BARATZ, 1962).

Celina Souza (2006), com didática e precisão, aponta quem seriam os "pais fundadores" da área de política pública. Concordando com a autora, destacamos os gigantes: Harold Laswell, que introduz em 1936 a expressão policy analysis (LASWEL, 1936), entendendo análise de política pública como a forma de estabelecer diálogo entre cientistas sociais, grupos de interesse e governo; Herbert Alexander Simon, que em 1957 introduziu o conceito de racionalidade limitada dos decisores públicos (policy makers); Charles Lindblom, em 1959, que adiciona outras variáveis, como as relações de poder, abrindo a importantíssima vereda na qual, além da racionalidade, as políticas públicas precisariam incorporar outros elementos à sua formulação e posterior análise, tais como: o papel das eleições e burocracias e dos partidos e grupos de interesse; David Easton (1965), em seu antológico trabalho A system analyses of political life, apresenta essencial colaboração para a área, ao definir a política pública como um sistema, ou seja, como uma relação entre a formulação, os resultados e o ambiente.

Inúmeros autores se esforçam na tentativa de definir o que é "política pública". Para fins deste trabalho, adotaremos o conceito objetivo de Thomas Dye (1972), em que esta corresponde às escolhas do que o Governo fará ou deixará de fazer. O sítio onde essas escolhas se materializam é o orçamento. Cabe-nos enfatizar a máxima: nenhuma despesa pública pode ser realizada sem estar fixada no orçamento. O Manual técnico do orçamento (BRASIL, 2020a) preceitua que o orçamento público é regido por princípios que visam estabelecer regras básicas a fim de conferir racionalidade, eficiência e transparência aos seus processos de elaboração, execu- 
ção e controle. A destinação dos recursos públicos dá-se por meio das leis orçamentárias, nome genérico para o trio integrado por: Plano Plurianual (PPA), Lei de Diretrizes Orçamentárias (LDO) e Lei Orçamentária Anual (LOA). Em alguns estados adita-se, ainda, uma lei de prazo maior para estabelecer uma visão de longo prazo para os objetivos do desenvolvimento. No caso do estado de Minas Gerais, os constituintes insculpiram no texto da Constituição Compromisso, a Constituição do Estado de Minas Gerais de 1989, a figura do Plano Mineiro de Desenvolvimento Integrado (PMDI), de iniciativa da sociedade e que consolida o conjunto de grandes escolhas para a construção do futuro do estado. A lei em vigência é a de número 23.577, de 15 de janeiro de 2020, que estabelece diretrizes para serem cumpridas até o ano de 2030. O objetivo do PMDI, por sua vez, é proporcionar as condições estruturantes fundamentais para um período prolongado e estável de crescimento econômico e social de forma sustentável. É, portanto, ferramenta essencial para mitigar as desigualdades regionais do estado e buscar a realização da coesão socioeconômica.

Outra peculiaridade da legislação do estado de Minas Gerais é o reconhecimento da importância do controle externo, via Tribunal de Contas, para aferição da efetividade da gestão municipal. Isto foi realizado ao incluir na Lei 23.685, de 7 de agosto 2020 (MINAS GERAIS, 2020), que dispõe sobre as diretrizes para elaboração e execução da lei orçamentária para o exercício de 2021 (LDO-MG, 2021), dispositivo que vincula a contrapartida a ser realizada pelo ente municipal no momento do repasse ao seu Índice de Efetividade da Gestão Municipal (IEGM-MG). Este índice é auferido pelo Tribunal de Contas do Estado de Minas Gerais e disponibilizado ao Instituto Rui Barbosa para o cálculo do IEGM-Brasil. Este marco pioneiro em legislação, de iniciativa do executivo, é o caminho para o reconhecimento da meritocracia de processos que visam a melhoria da administração pública brasileira. Assim, a cultura de aprimoramento das estratégias de gerenciamento da "coisa" pública torna-se cada vez mais 
inerente àqueles que são responsáveis pela gestão.

Shepsle e Weintgast (1981) e seus colegas do Instituto para a Ciência Social, no Departamento de Governo, da Universidade de Harvard, têm sido uma referência para a análise da política. A introdução do termo winset, cunhado por Shepsle e Weingast em 1981, mostra a complexidade do "conjunto que vence" e a necessidade da imparcialidade institucional para a validade da racionalidade.

Serra (2016), discípulo de Shepsle e professor da prestigiada Divisão de Estudos Políticos do Centro de Investigação e Docência Econômica (CIDE), no prólogo da obra Analizar la Política, ao descrever a relevância dos atores políticos e suas estratégias e a eleição racional indica a complexidade da política em razão da quantidade de atores políticos que tratam de ter influência nas decisões governamentais com objetivos muito diversos e contraditórios. Em sua dicção,

Chefes de Estado, legisladores, juízes e militares são alguns dos funcionários públicos que buscam incidir no processo governamentais. Também existe em seu número de atores não governamentais - eleitores, organizações da sociedade civil, empresários, sindicatos e outros - que pretendem deixar a sua marca no país e nos países vizinhos. Os atores em ambições políticas, sempre enfrentam contextos complicados que requerem estratégias bem desenhadas, o que exige a todo momento, calcular o melhor uso possível dos recursos de acordo com suas metas (SHEPSLE, 1997, p. 17).

Entre nós, na mesma esteira, Secchi (2019, p. 23) estabelece que "ao conjunto de diretrizes e intervenções do Estado, feitas por pessoas físicas e jurídicas, públicas ou privadas, com vistas a tratar o problema público, dá-se o nome de políticas públicas.” Em apertada síntese, vale a diferenciação entre os problemas coletivos (que existem independentemente dos governos e afetam uma coletividade de qualquer natureza) e problemas públicos (aqueles que os governos tomaram para si, seja na forma de ação ou deliberada não ação). 
O Tribunal de Contas da União, ao publicar a recente Portaria-TCU $\mathrm{n}^{\mathrm{o}} 188$, de 30 de novembro de 2020, que opera o referencial de controle de políticas públicas (RC-PP), adita:

Considerando o mandato e as competências dos órgãos de controle externo no Brasil, para fins do presente Referencial de Controle de Políticas Públicas, são consideradas políticas públicas o conjunto de intervenção e diretrizes emanadas de atores governamentais, que visam tratar ou não, problemas públicos e que requerem, utilizam ou afetam recursos públicos.

Superada a conceituação de políticas públicas, passaremos ao tema da avaliação destas.

\section{AVALIAÇÃO DE POLÍTICAS PÚBLICAS}

Mantendo a complexidade diagnosticada e apontada do termo "políticas públicas", a palavra "avaliação" também pode ser compreendida em múltiplos conceitos. Michael Scriven (2018), em seu Avaliação: um guia de conceitos, anota 74 verbetes para este conceito, afirmando que "avaliação é o processo de determinação do mérito, importância e valor das coisas, e as avaliações são os produtos deste processo".

O Guia Prático de Análise Ex Ante recomenda que

a avaliação de políticas públicas deve começar no nascedouro, por meio da análise ex ante, a fim de verificar, fundamentalmente, se respondem a um problema bem delimitado e pertinente. [...] Entre outros tópicos, é necessário, que as políticas públicas contem com esta análise ex ante tem para que os recursos públicos e o bem-estar da sociedade sejam otimizados (BRASIL, 2018a, p. 11-20).

A análise ex ante é indicada para a criação de política pública, na respectiva expansão que acarrete aumento de valor da programação orçamentária e no aperfeiçoamento que implique alteração no seu desenho. 


\section{O Guia Prático de Análise Ex Post destaca que a}

avaliação ex post, é o instrumento relevante para a tomada de decisões ao longo da execução da política - dizendo ao gestor o que aprimorar, e em alguns casos, como fazê-lo - bem como para melhor alocação de recursos entre as diferentes políticas públicas setoriais. [...] É importante diferenciá -la do monitoramento. Além disso, a avaliação deve ser conduzida preferencialmente por outros órgãos independentes, não diretamente responsáveis pela execução da política pública, como os órgãos centrais, o Ipea e o Tribunal de Contas da União, bem como as universidades e fundações privadas, mediante interação com o gestor responsável pela política pública (BRASIL, 2018b, p. 13-35).

Pontes Lima e Mendonça Diniz (2018, p. 401) destacam a clareza das atualizações do controle externo e do gestor:

O artigo 70 da CF estabelece que a fiscalização engloba as dimensões da legalidade, da economicidade e da legitimidade. Não basta, portanto, avaliar que determinado gasto público está em conformidade com a legislação, mas cabe verificar se está em sintonia com critérios de economia e se atende anseios legítimos.

É claro que há sempre espaço para discricionariedade do gestor público, sendo vedado ao órgão de controle substituí-lo na tomada de decisões. [...] O administrador público, ao contrário, deve tomar decisões que levem em conta a agregação de valor para a sociedade (value for money), decisões devidamente amparadas nas melhores técnicas, que avaliem custos e benefícios.

Neste sentido deve ser valorada a dicção de Daron Acemoglu (2015, p. 58-59): em que "o caminho a seguir em direção às instituições inclusivas é o fortalecimento da mídia, do judiciário e dos órgãos de controle." Esta opção, ser instituição inclusiva e não extrativista, nos moldes preconizados por Acemoglu e Robinson (2012), no aclamado Por que as nações 
fracassam, faz parte das diretrizes da Intosai ${ }^{3}$ (International Organization of Supreme Audit Institution) desde 1971, quando Andrew Maxwell Henderson, auditor geral do Canadá, no VII Incosai ${ }^{4}$ formaliza a proposta de auditoria operacional.

Em 1992, no XIV Incosai, realizado em Washington, ocorre a criação do Grupo de Trabalho de Avaliação de Programas. A linha histórica da opção inclusiva tem segmento em 2004 com o reconhecimento formal da Avaliação de Políticas Públicas e Programas como uma das atividades das Entidades Fiscalizadoras Superiores ${ }^{5}$; simultaneamente é criada a ISSAI 300, que no arcabouço brasileiro corresponde à NBASP 300.

Em 2010 o Grupo de Estudos de Políticas e Programas da Intosai (identificado pela sigla em inglês WGEPPP e liderado pelo Tribunal de Contas da França) apresenta o primeiro documento publicado pelo WGEPPP, consolidado como A Primer ${ }^{6}$. Esta vereda foi ampliada após amplo debate, resultando em 2016 na Intosai GOV9400, primeira publicação que contempla as "Diretrizes para Avaliação de Políticas" no âmbito do controle externo, que se consolida no XXIII Incosai ${ }^{7}$ na GUID 9020.

É justo homenagear neste momento brasileiros e brasileiras que tiveram o pioneirismo de tratar do tema da auditoria operacional nos tribunais de contas do nosso país e o fazemos por meio da figura do VicePresidente do Instituto Rui Barbosa, Inaldo da Paixão Santos Araújo, conselheiro do Tribunal de Contas da Bahia que em 2001 nos brindava com a sua obra Introdução à auditoria operacional.

3 The International Organization of Supreme Audit Institutions: organização não governamental fundada em 1953 em Havana, Cuba. Sua sede está localizada na cidade de Viena, Áustria. Endereço eletrônico: www.intosai.org 4 VIII, Incosai. O Congresso foi realizado em Montreal, Canadá e contou com a participação de 72 entidades fiscalizadoras superiores.

$5 \quad$ O grupo de trabalho da Intosai sobre a avaliação de programas foi criado em 1992, com o papel de apoiar as Entidades Fiscalizadoras Superiores, ligado ao Comitê de Conhecimento (KSC). Atualmente o grupo é constituído de 22 EFS: Alemanha, Bélgica, Chile, Costa Rica, Estados Unidos, Finlândia, França, Gabão, Geórgia, Hungria, Quênia, Líbia, Lituânia, México, Marrocos, Paquistão, Filipinas, Papua Nova Guiné, Polônia, República da Coreia, República de Salvador e Suíça.

6 Em 2010, no XX Incosai, realizado em Joanesburgo, é aprovado o primeiro documento sobre avaliação de programas (Premier). Apresenta o conceito de avaliação, substitui o termo avaliação de programas por avaliação de políticas públicas e faz as recomendações para o planejamento de uma avaliação. Conclui apontando a existência de uma fronteira entre a avaliação e a ingerência política, que não deve ser ultrapassada sob nenhum pretexto.

7 A diferença entre auditoria operacional e avaliação de política pública, na ótica do controle externo, pode ser estabelecida com a interpretação acurada do parágrafo 9 da ISSAI 300 (NBASP 300) e a definição de objetivos e limites da avaliação de políticas públicas estabelecidas na GUID 9020. 


\title{
3 TRIBUNAIS DE CONTAS E DEMOCRACIA
}

\author{
É oportuno iniciar o tema com a dicção de William Blackstone \\ (1759), que nos alerta sobre o impacto resultante das nossas ações ou \\ omissões:
}

Daqui a apenas algumas gerações chegará o milênio da Magna Carta; não está minimamente claro se a data será celebrada, deplorada ou ignorada". A parte mais famosa da Carta de Diretrizes é o Artigo 39: "nenhum homem livre será capturado ou aprisionado de modo algum, nem nós procederemos contra ele ou o perseguiremos, exceto pelo julgamento legítimo de seus pares ou pela lei do país. ${ }^{8}$

\section{O destacado jusfilósofo mineiro José Luiz Borges Horta (2011, p. 46) leciona:}

\begin{abstract}
A caminho da Liberdade, os homens consagram valores complementares, traduzidos em momentos sucessivos numa história coerente. Parece-nos que o Estado de Direito possui três grandes momentos (e seus consequentes paradigmas):

1. O Estado Liberal de Direito, forjado na Era das Revoluções;

2. O Estado Social de Direito, exigido desde meados do século XIX (sobretudo, com o Manifesto Comunista de 1848) e consagrado, como se verá, na República alemã de Weimar, cuja Constituição data de 1919;

3. O Estado democrático de Direito, esboçado na Declaração Universal; dos Direitos do Homem 1948, e ainda em processo de construção (intelectual, normativa e fática).
\end{abstract}

Por hipótese, as três gerações de direitos fundamentais concedem fundamentos jusfilosóficos aos três paradigmas de Estado de Direito. Os tribunais de contas perpassam estes momentos históricos e tornam-se instituições essenciais à democracia, na medida em que atuam nas vertentes

8 A edição de Blackstone contém duas cartas. A primeira, a Carta de Direitos, é reconhecida como o alicerce dos direitos fundamentais e é acompanhada da Carta da Floresta, que talvez seja a mais relevante. Esta carta exigia a proteção dos bens comuns e está guardada na Biblioteca Britânica. 
da transparência, da prestação de contas e da avaliação das políticas públicas, dando oportunidade para uma nova fronteira que exigirá dos órgãos de controle uma capacitação aditiva para o exercício da missão institucional.

Consideramos a data de 2004 e a iniciativa do controlador geral dos Estados Unidos - David M. Walker (2004) - como marco histórico desta mudança de paradigma. É o instante em que o órgão de controle estadunidense deixa de ser General Accounting Office para se tornar Government Accountability Office, mantendo o lendário acrônimo da instituição (GAO). A justificativa da troca de nomes sinaliza uma mudança paradigmática. A troca de nomes é um pequeno passo, mas quer dizer que a necessidade de transformar o foco de atuação é a razão da instituição ser revoltante no século XXI. Deve-se destacar que já no primeiro parágrafo do documento David Walker colaciona que, após 83 anos, "contas" nunca foram a missão do órgão, mas sim a economicidade, a eficiência e a efetividade do governo.

Hodiernamente, uma visita ao portal dos 33 Tribunais de Contas brasileiros permite inferir esta mudança na missão institucional. Vejamos alguns exemplos colhidos aleatoriamente de modo a contemplar cada uma das regiões do Brasil:

Tribunal de Contas da União:

Controlar a Administração Pública para contribuir com o seu aperfeiçoamento em benefício da sociedade. ${ }^{9}$

Tribunal de Contas do Estado do Amazonas:

Exercer o controle externo da gestão dos recursos públicos por meio de ações de orientação e fiscalização em benefício da sociedade amazonense. ${ }^{10}$

$\begin{array}{ll}9 & \text { Disponível em: www.tcu.gov.br } \\ 10 & \text { Disponível em: http://www.tce }\end{array}$

10 Disponível em: http://www.tce.am.gov.br/ 
Tribunal de Contas do Estado do Ceará:

Ser guardião dos recursos públicos estaduais, contribuindo para o aprimoramento da governança e da gestão pública em benefício da sociedade. ${ }^{11}$

Tribunal de Contas do Estado de Minas Gerais:

Exercer o controle externo da gestão dos recursos públicos de forma eficiente, eficaz e efetiva, em benefício da sociedade. ${ }^{12}$

Tribunal de Contas do Estado do Mato Grosso:

Garantir o controle externo da gestão dos recursos públicos, mediante orientações, fiscalização e avaliação de resultados, contribuindo para a qualidade e a efetividade dos serviços, no interesse da sociedade. ${ }^{13}$

Tribunal de Contas do Estado do Rio Grande do Sul:

Exercer o controle externo sobre a gestão do Estado e dos $\mathrm{Mu}$ nicípios do Rio Grande do Sul, em conformidade com as regras e os princípios constitucionais, contribuindo para o aperfeiçoamento da Administração Pública, em benefício da sociedade. ${ }^{14}$

Um traço comum a todas as assertivas colacionadas dos respectivos portais é a constante preocupação com o "benefício da sociedade", denotando - de maneira inquestionável - a supremacia do interesse público, típica e inerente à administração pública. Emerge então a seguinte pergunta: "Como atuar em benefício da sociedade?" A própria Intosai, em 2013, ao aprovar a Issai 12 (NBASP 12), chamada de "Valor e Benefícios das Entidades Fiscalizadoras Superiores fazendo a diferença na vida dos cidadãos", no seu preâmbulo confirma:

\footnotetext{
11 Disponível em: http://www.tce.ce.gov.br/

12 Disponível em: http://www.tce.mg.gov.br/

13 Disponível em: http://www.tce.mt.gov.br/

14 Disponível em: http://www.tce.rs.gov.br/
}

Rev. Controle, Fortaleza, v. 19, n.1, p. 21-38, jan./jun. 2021. 
Desta forma, as EFS promovem a eficiência, accountability, efetividade e transparência da Administração Pública. Uma EFS independente, efetiva e confiável é, portanto, um componente essencial num sistema democrático em que accountability, transparência e integridade são partes indispensáveis de uma democracia estável (INSTITUTO RUI BARBOSA, 2020, p. 8).

\section{Prossegue o documento:}

Em uma democracia, as estruturas são criadas e representantes eleitos são empoderados para implantar a vontade do povo e agir em seu nome por meio de órgãos legislativos e executivos. Um risco a ser considerado em instituições do setor público em uma democracia é que o poder e os recursos podem ser mal utilizados, levando a uma erosão da confiança que pode minar a essência do sistema democrático [...] As EFS podem evidenciar sua relevância respondendo adequadamente aos desafios dos cidadãos, às expectativas das diferentes partes interessadas e aos riscos emergentes e mudanças de ambiente em que as auditorias são realizadas.

Os princípios estabelecidos neste documento são construídos em torno da expectativa fundamental das EFS fazerem a diferença na vida dos cidadãos. O impacto da EFS na vida de uma população depende que a EFS:

- Fortaleça a accountability, transparência e integridade das entidades governamentais e do setor público;

- Demonstre a relevância contínua para os cidadãos, o Legislativo e outras partes interessadas, e'

- Seja um modelo de organização, liderando pelo exemplo (THE INTERNATIONAL ORGANIZATION OF SUPREME AUDIT INSTITUTIONS, 2019).

\section{É hora de realçar o princípio federativo na organização política do Brasil. A Constituição da República Federativa do Brasil (BRASIL, 1988) já anuncia em seu art. $1^{\mathrm{o}}$ :}

A República Federativa do Brasil, formada pela união indissolúvel dos Estados e Municípios e do Distrito Federal, constituise em Estado democrático de Direito e tem como fundamentos: 
I - a soberania;

II - a cidadania;

III - a dignidade humana;

IV - os valores sociais do trabalho e da livre iniciativa;

$\mathrm{V}$ - o pluralismo político.

A atual Ministra do Supremo Tribunal Federal, a mineira Carmem Lúcia Antunes Rocha leciona:

O princípio federativo compõe-se dos seguintes elementos:

Da soberania nacional e das autonomias locais das entidades componentes do Estado;

Da repartição de competências entre estas entidades, o que assegura a sua personalização política e o âmbito de competência autonomia e exclusiva de cada qual;

Da participação de todas elas na formação da vontade nacional (SERAFIN, 2014).

Pode-se inferir, então, que a soberania é nacional, e a União, os estados, o Distrito Federal e os municípios são autônomos, o que implica dizer que no Brasil não existe - como vasta literatura insiste em replicar - os chamados "entes subnacionais", pois todos são entes federativos. Na mesma esteira é evidente que não temos uma Entidade Fiscalizadora Superior (embora o Tribunal de Contas da União seja afiliado à Intosai), pois todos os 33 tribunais de contas do Brasil são, de fato, Entidades Fiscalizadoras Superiores, visto que não há nenhum grau de hierarquia entre eles, sendo todos autônomos na forma das leis que os regem. ${ }^{15}$

Espera-se, portanto, o fortalecimento da democracia com a contribuição dos órgãos de controle ao abraçarem esta novíssima competência, mantendo a atenção também nas tradicionais auditorias (NBASP 100), com a categorização de auditorias de conformidade (NBASP 200), audi-

15 O Instituto Rui Barbosa e a Casa do Conhecimento dos Tribunais de Contas do Brasil, vêm trabalhando para a adoção das Normas Brasileiras de Auditoria do Setor Público (NBASP, Livro Azul da Auditoria) e a publicação do "INTOSAI GOV9400 - Orientações para a avaliação de políticas públicas", aprovada em 2016, com o estabelecimento na Estrutura de Pronunciamentos. Profissionais da INTOSAI (IFPP), foi renomeada GUID 9020 Avaliação de Políticas Públicas", incorporando as alterações propostas em 2019 no Congresso de Moscou. Em 2020, o IRB trabalha na sua tradução e adaptação com a proposta da NBASP 9020. 
torias operacionais (NBASP 300) e auditorias financeiras (NBASP 400), mas dando um passo rumo ao futuro, com a avaliação da política pública (NBASP 9020). Não abordaremos aqui a clássica distinção entre auditoria operacional (foco nos 4 e's: economicidade, efetividade, eficiência e eficácia) e avaliação de políticas públicas (foco na política pública em si, e não no agente que a executa), mas encerraremos este artigo com citações do Presidente do Tribunal de Contas da França, Pierre Moscovici, no painel organizado pelo Instituto Rui Barbosa, em 20 de novembro, em discurso por videoconferência no Encontro Nacional dos Tribunais de Contas do Brasil, oportunidade em que asseverou:

\begin{abstract}
A finalidade de uma avaliação é, portanto, ajudar a formular uma avaliação do impacto socioeconômico geral de uma política pública, em relação aos seus objetivos, a fim de ajudar a melhorar sua relevância e utilidade real [...] A contribuição que oferece para o debate democrático é essencial porque é neutra e baseada apenas em fatos, sem necessariamente advogar uma solução única. A avaliação das políticas públicas permite, portanto, aos cidadãos e aos tomadores de decisão, formar sua própria opinião na hora de decidir ou aderir a uma política com base em informações claras e verificadas. [...]

O desenvolvimento do trabalho de avaliação requer, portanto, um investimento técnico e humano, mas estamos convictos de que pode conduzir a uma ação pública mais esclarecida, eficaz e compreendida pelos nossos concidadãos. Nesse sentido, a avaliação de políticas públicas é um instrumento estruturante da democracia.
\end{abstract}

Esta é a vereda a ser percorrida! Um desafio enorme para o sistema de controle externo do Brasil, que certamente não faltará aos brasileiros e brasileiras, que necessitam de bom governo e contam com os Tribunais de Contas para auxiliarem na melhor aplicação dos recursos públicos, visando o impacto transformador das políticas públicas. 


\section{CONCLUSÃO}

A conclusão deste artigo é que a participação dos Tribunais de Contas na avaliação de políticas públicas, nos moldes preceituados pela NBASP 9020, inaugura um novo tempo do controle externo brasileiro. Celebra, em outras palavras, uma nova visão dialógica, não sancionadora e pautada na participação das partes interessadas na política pública em análise, visando maior relevância e impacto na escolha de atitudes que melhoram a qualidade de vida das pessoas.

\section{REFERÊNCIAS}

ACEMOGLU, D. CONGRESSO INTERNACIONAL DE CONTROLE E POLÍTICAS PÚBLICAS, 1., 2015, Belo Horizonte. Anais [...]. Belo Horizonte: Instituto Rui Barbosa.

ACEMOGLU, D.; ROBINSON, J. A. Por que as nações fracassam: as origens do poder, da prosperidade e da pobreza. Rio de Janeiro: Elsevier, 2012.

ARROW, K. Social choice and individual values. New Haven: Yale University Press, 1951.

BACHRACHB, P.; BARATZ, M. S. Two faces of power. American Political Science Review, Washington, DC, v. 56, p. 947-952, 1962.

BLACKSTONE, W. The great charter and charter of the forest. Oxford: [s. n.], 1759.

BRASIL. Constituição da República Federativa do Brasil. Brasília, DF, 1988. 
BRASIL. Avaliação de Políticas Públicas: guia prático de análise ex ante. Brasília, DF: Ipea, 2018a. v. 1.

BRASIL. Avaliação de Políticas Públicas: guia prático ex post. Brasília, DF: Ipea, 2018b. v. 2.

BRASIL. Manual Técnico de Orçamento - MTO 2020. 14. ed. Brasília, DF, 2020a. Disponível em: https://bit.ly/3m20L9U. Acesso em:19 nov. 2020.

BRASIL. Portaria TCU no 188, de 30 de novembro de 2020: aprova o referencial de controle de Políticas Públicas. Boletim do Tribunal de

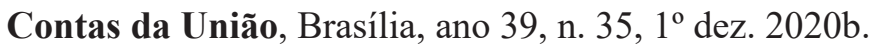

DYE, T. D. Understanding public policy. Englewood Cliffs: Pretice Hall, 1984.

EASTON, D. A system analyses of political life. New York: John Wiley and Sons, 1965.

HORTA, J. L. B. História do Estado de direito. São Paulo: Alameda, 2011.

INSTITUTO RUI BARBOSA. NBASP 12: Valor e benefícios da avaliação dos tribunais de contas para a sociedade. Brasília, DF, 2020.

LASWEL, H. D. Who gets what, when, how. New York: Whittlesey House, McGraw-Hill, 1936.

LIMA, E. C. P.; DINIZ, G. M. Avaliação de políticas públicas pelos tribunais de contas: fundamentos, práticas e a experiência nacional e internacional. In: 
SACHSIDA, A. (org.). Políticas públicas: avaliando mais de meio trilhão de reais em gastos públicos. Brasília, DF: Ipea, 2018. p. 399-416.

LINDBLOM, C. E. The science of muddling through. Public Administration Review, v. 19, n. 2, p. 79-88, 1959.

MINAS GERAIS. Projeto de Lei $\mathrm{n}^{\mathrm{o}} 1.996 / 2020$, transformado na Lei $\mathrm{n}^{\mathrm{o}} 23.685$, de 7 de agosto de 2020. Diário do Executivo, Belo Horizonte, col. 2, 8 ago. 2020.

MOSCOVICI, P. A experiência do Tribunal de Contas da França na avaliação de políticas públicas. In: Encontro Nacional dos Tribunais de Contas, 7., 2020, Brasília, DF. Anais [...]. Brasília, DF: Instituto Rui Barbosa, 2020.

SCRIVEN, M. Avaliação: um guia de conceitos. Rio de Janeiro: Paz e Terra, 2018.

SERAFIN, G. P. O princípio federativo e a autonomia dos entes federados. Porto Alegre, 2014. Disponível em: https://bit.ly/37SuFZf. Acesso em: 9 dez. 2020.

SECCHI, L. Análise de políticas públicas: diagnóstico de problemas, recomendação de soluções. São Paulo: Cengage Learning, 2019.

SERRA, G. Analizar la politica: comportamento, instituciones y racionalidade. Ciudad de México: Centro de Investigación y Docencia Económicas, 2016.

SHEPSLE, K. A. Analyzing politics: rationally behavior and institutions. New York: WW Norton \& Company, 1997. 
SHEPSLE, K. A.; WEINGAST, B. R. Structure-induced equilibrium and legislative choice. Public Choice, Medford, n. 37, p. 503-519, 1981.

SIMON, H. A. Models of man: social and rational human behavior in a social setting. New York: John Wiley and Sons, 1957.

SOUZA, C. Políticas públicas: uma revisão da literatura. Sociologias, Porto Alegre, n. 16, p. 20-45, 2006.

THE INTERNATIONAL ORGANIZATION OF SUPREME AUDIT INSTITUTIONS. INTOSAI $-\mathrm{P}-12$ : The value and benefits of supreme audit institutions making a difference to the lives of citizens. Viena, 2019. Disponível em: https://bit.ly/39XjgtM. Acesso em: 9 dez. 2020.

WALKER, D. M. GAO Answers the question: what's in a name? 2004. Disponível em: https://bit.ly/372r63s. Acesso em: 9 dez. 2020. 